\title{
Do Prediction Markets Aid Defenders in a Weak-Link Contest?
}

\author{
Cary Deck ${ }^{a}$ \\ Li Hao ${ }^{b}$ \\ David Porter
}

November 2013

\begin{abstract}
Laboratory experiments have demonstrated that prediction market prices weakly aggregate the disparate information of the traders about states (moves) of nature. However, in many practical applications one might want to predict the move of a strategic participant. This is particularly important in aggressor-defender contests. This paper reports a set of such experiments where the defender may have the advantage of observing a prediction market on the aggressor's action. The results of the experiments indicate that: the use of prediction markets does not increase the defender's win rate; prediction markets contain reliable information regarding aggressors' decisions, namely excess bid information, that is not being exploited by defenders; and the existence of a prediction market alters the behavior of the aggressor whose behavior is being forecast.

Keywords: Information Aggregation, Prediction Markets, Weak-Link Contests, Colonel Blotto JEL: C7, C9, D7, D8, G1
\end{abstract}

a. Cary Deck (corresponding author), 402 WCOB, Department of Economics, University of Arkansas, Fayetteville, AR 72701 and Economic Science Institute, Chapman University. email: cdeck@walton.uark.edu, phone +1 479575 6226, fax +1 4795753241.

b. Li Hao, 402 WCOB, Department of Economics, University of Arkansas, Fayetteville, AR 72701. email: Ihao@walton.uark.edu.

c. David Porter, Economic Science Institute, Chapman University, One University Drive, Orange, CA 92866. email: dporter@chapman.edu 


\section{Introduction}

Prediction markets have gained popularity in recent years as a means of aggregating diversely held information. Chen and Plott (2002) implement prediction markets for sales forecasts at Hewlett-Packard Corporation (HP) and report that these markets outperform more traditional statistical forecasts. Cowgill et al. (2009) document that internal prediction markets at Google perform well for forecasting new office openings, launch dates, etc. Other effective prediction markets include those for movie box office receipts (Pennock et al. 2001), election outcomes (Berg et al. 2003), outbreaks of contagious diseases (Polgreen et al. 2007) and slaughtered cattle (Gallardo 2009). Still there remain many more applications where prediction markets could be utilized, but are not (see Wolfers and Zitzewitz 2004). For example, Hahn and Tetlock (2005) propose using prediction markets to set monetary policy. After the terrorist attacks of September 11, 2011, Policy Analysis Markets (PAM) were proposed by the Defense Advanced

Research Projects Agency, but these markets were not implemented due to concerns raised by members of Congress (Pearlstein 2003; Wyden and Dorgan 2003).

A common, but generally inaccurate, concern for prediction markets is that they can be easily manipulated (see Deck and Porter (2013) for a review). Deck et al. (2013) demonstrate that prediction markets can be manipulated when traders only get returns from manipulation and have a large bankroll. The other main concern in many countries including the United States involves the ambiguous legal status of prediction markets, due to resemblance with gambling. Prior to halting operations in March 2013, Intrade.com operated public prediction markets on a wide range of future events, including politics, economics, and entertainment, but had spun off the now defunct TradeSports.com which focused exclusively of forecasting the outcome of sporting events years earlier. In Arrow et al. (2008) a group of 22 prominent scholars called for government policies, especially gambling laws, to be relaxed in order for decision makers to better utilize prediction markets.

Concerns of manipulation and gambling are largely mitigated with internal prediction markets, where only members within an organization can participate using token money given to them (as opposed to Intrade where the general public traded shares using money out of their own pockets). The markets at HP were only open to employees in the fields of marketing and finance (Chen and Plott 2002). The proposed PAM markets were to be open only to those inside the defense community. Trades on Google's internal market are denoted in Goobles (Cowgill 2009). Absent these two main concerns, it is easy to see why there are many advocates for increased reliance on prediction markets given their demonstrated success in a variety of settings (see for Wolfers and Zitzewitz 2004).

Despite the rhetoric around prediction market success, these markets are typically quite noisy in the laboratory. As discussed in a recent survey by Deck and Porter (2013), average 
prices in a period tend to be too high and over a series of trading periods the variance in average prices tends to be too small in comparison to full information aggregation prediction. Nonetheless, closing prices contain useful information as they correlate positively - although weakly - with the prices that should prevail when information is aggregated, at least after the traders have gained market experience. Even such imperfect prediction markets can provide useful information to market observers (see Oprea et al. 2007). However, unlike previous laboratory experiments where the forecasted event is exogenous, in many naturally occurring settings the activity that is being forecasted involves strategic uncertainty in a larger game. For example, one can imagine a firm using a prediction market to forecast which market segments a rival is going to target with its advertising budget. The goal is not simply to aggregate this information, but to use the information in allocating the firm's own advertising budget. The same situation would have arisen in the PAM markets where the forecasted activity would have involved the calculated actions of terrorists who were attempting to hide their actions from those in the defense community.

Endogeneity raises two issues for prediction markets that are absent with exogenous information. The first is that the type of behavior that is being forecast may change due to the existence of the prediction market. The second is that traders may be more likely to rely upon their own intuition or bias about what the forecasted behavior is likely to be rather than focusing on their private information. For example, a trader forecasting a rival's advertising efforts in a particular market may be subject to a confirmation bias and overweight their prior belief that the rival is going to invest heavily on a certain market segment. A defense analyst may ignore private information suggesting one target is unlikely to be attacked out of a conviction that it is the obvious choice of target.

The current paper explores the effectiveness of internal prediction markets where the forecasted event is an endogenous choice in a game between the market observer and the party whose actions are being forecasted. Formally, the game is modeled as a weak-link contest, a type of game that has received considerable behavioral and theoretical attention recently (see Dechenaux et al. 2012 and Kovenock and Roberson 2010 for comprehensive reviews of the respective literatures). The paper is organized as follows. The next section discusses background details. Section 3 describes the experimental design and Section 4 provides the behavioral results. A final section offers a concluding discussion.

\section{Background}

Contests have been used to study a variety of topics: lobbying (Krueger, 1974; Tullock, 1980; and Synder 1989), patent races (Fudenberg et al., 1983; Haris and Vickers, 1985, 1987), and military strategy (Borel, 1921; Borel and Ville, 1938; Gross, 1950; Gross and Wagner, 1950 and Freidman, 1958). The essential components of a contest are that each player makes an 
unrecoverable investment in the hopes of earning a prize, the allocation of which depends in part on the set of realized investments. One common approach is the so called all-pay auction where the party investing (or bidding) more wins with certainty.

Conceptually it is straightforward to extend a single all-pay auction to a series of contests where the ultimate winner depends on combinations of outcome of the individual contests. Many sporting champions are determined by playing a best of five or best of seven series. New products often involve a series of patents rather than a single patent. Firms often compete with each other in multiple markets. Terrorists have many possible targets. The classic Colonel Blotto game (Borel 1921) is a multi-contest game where the two militaries simultaneously allocate discrete numbers of soldiers among different battlefields. A battle is won by the military with more troops present and the war is won by the military that wins the most battles. Despite the relatively simple set up, this problem is quite complex and only finally solved for all symmetric discrete Colonel Blotto games by Hart (2008). Other recent work in the area has allowed for asymmetric budget, an opportunity cost of resources, continuous investment, and non-majority win rules (see Kvasov, 2007; Laslier, 2002; Laslier and Picard, 2002; Roberson, 2006; Szentes and Rosenthal 2003a, b). Clark and Konrad (2007) and Golman and Page (2009) consider a weakest link structure where one side needs to win every battle to win the war while the other side only needs a single victory.

In the laboratory, Avrahami and Kareev (2009) examine Colonel Blotto games with symmetric and asymmetric budgets. The results are qualitatively consistent with the theoretical predictions. Cinar and Goksel (2012) also report aggregate behavior in Blotto games that is consistent with the theoretical predictions (see also Arad 2012; Arad and Rubinstein 2012; Chowdhury, et al. 2013).

What has not received much attention in the contest literature is sequential all pay auctions, weak link or otherwise. The reason is that the solution is obvious and favors the last mover. However, if a successful prediction market that was completely aggregating information were in operation, the simultaneous move game would essentially become an uninteresting sequential game that could be dominated by the contestant who observed the prediction. Thus, these types of contests are exactly where one would want to implement a prediction market. Further, given the clear effect a functioning prediction market should have, this is an ideal environment for exploring prediction markets for endogenous actions.

Another advantage of the discrete weak-link contest for the purpose of this paper is that the strategy space lends itself well to the types of exogenous environments that have been used to study prediction markets. The classic information aggregation experiment by Plott and Sunder (1988) involved three possible states of the world where each traders was informed of one of the unrealized states in such a way that the market as a whole had complete 
information. Anderson and Holt (1997) and Hung and Plott (2001) consider a world with only two states; but in which traders only observe a noisy signal of the realized state. With only two possible states a single state specific asset can capture all of the relevant information. Again the behavioral results were that prices do a reasonable job of aggregating information. The reported success of prediction markets should not be construed to mean that prices are typically correct in the laboratory (see Manski 2006 and Gjerstad 2005 for a theoretical discussion of the divergence in beliefs and equilibrium prices). In the lab, prices are often too high but absent active manipulation market observers are typically able to take this bias into account to some degree when interpreting market behavior (Oprea, et al. 2007; Deck, et al. 2013). Given the previous success and the operational simplicity of prediction markets with only two states as in Anderson and Holt (1997) and Hung and Plott (2001), the contest used in the current paper is restricted to two battlefields. Following Plott and Sunder (1988), the market participants as a whole have complete information, which is achieved by each trader in the market observing one of the discrete units that the player whose actions are being forecasted has to available to allocate.

\section{Experimental Design}

The experiment involves two interconnected pieces drawing from the background literature discussed above: a contest game and a prediction market. These two components are described in detail separately and then the specific treatments and procedures that were used are presented.

\subsection{Weak-Link Contest Setup}

One player (the aggressor) has a budget of 5 tokens to allocate discretely between two contests, $A$ and $B$. The other player (the defender) has 6 tokens to allocate between the two contests. In each contest, whoever invests the most wins, and ties are broken in favor of the defender. However, the defender must win both contests to claim a prize $P_{2}$, while the aggressor only need to win one contest to claim a prize $P_{1}$. Table 1 gives the normal form representation of the game. Since there is no opportunity cost associated with the tokens, each player will always bid her entire endowment and thus strategies are completely identified by the number of tokens bid on A. During the experiment, neutral terms such as first mover and second mover were used instead of aggressor and defender. ${ }^{1}$

The game shown in Table 1 can be thought of as an advertising game between a smaller new entrant (the aggressor) and a larger incumbent (the defender). Both firms can buy air time for commercials targeted to different customer segments where each segment will purchase

\footnotetext{
${ }^{1}$ The contest is a simultaneous play game. The reason for having sequential names is discussed below.
} 
from the firm that courts it more. In such a case it is reasonable to assume that the incumbent has some small brand awareness by nature of having been in the market previously and would thus win a tie. Here $P_{1}$ can be thought of as the benefit to the new entrant from capturing one of the market segments whereas $P_{2}$ can be viewed as the marginal benefit to the incumbent of serving both segments rather than one. Alternatively, the game in Table 1 can be thought of as being played between a group of suicide bombers (the aggressor) and the police (the defender). The terrorists are successful if they can blow up either of two targets, which they can do if they outnumber the police at that location.

Table 1. Normal Form Game Representation of Strategic Contest

Tokens Invested in Contest A by Aggressor Tokens Invested in Contest A by Defender

\begin{tabular}{c|c|c|c|c|c|c|c|}
\multicolumn{10}{c}{ Tokens Invested in Contest A by Defender } \\
& 0 & 1 & 2 & 3 & 4 & 5 & 6 \\
\hline 0 & $\left(0, P_{2}\right)$ & $\left(0, P_{2}\right)$ & $\left(P_{1}, 0\right)$ & $\left(P_{1}, 0\right)$ & $\left(P_{1}, 0\right)$ & $\left(P_{1}, 0\right)$ & $\left(P_{1}, 0\right)$ \\
\hline 1 & $\left(P_{1}, 0\right)$ & $\left(0, P_{2}\right)$ & $\left(0, P_{2}\right)$ & $\left(P_{1}, 0\right)$ & $\left(P_{1}, 0\right)$ & $\left(P_{1}, 0\right)$ & $\left(P_{1}, 0\right)$ \\
\hline 2 & $\left(P_{1}, 0\right)$ & $\left(P_{1}, 0\right)$ & $\left(0, P_{2}\right)$ & $\left(0, P_{2}\right)$ & $\left(P_{1}, 0\right)$ & $\left(P_{1}, 0\right)$ & $\left(P_{1}, 0\right)$ \\
\hline 3 & $\left(P_{1}, 0\right)$ & $\left(P_{1}, 0\right)$ & $\left(P_{1}, 0\right)$ & $\left(0, P_{2}\right)$ & $\left(0, P_{2}\right)$ & $\left(P_{1}, 0\right)$ & $\left(P_{1}, 0\right)$ \\
\hline 4 & $\left(P_{1}, 0\right)$ & $\left(P_{1}, 0\right)$ & $\left(P_{1}, 0\right)$ & $\left(P_{1}, 0\right)$ & $\left(0, P_{2}\right)$ & $\left(0, P_{2}\right)$ & $\left(P_{1}, 0\right)$ \\
\hline 5 & $\left(P_{1}, 0\right)$ & $\left(P_{1}, 0\right)$ & $\left(P_{1}, 0\right)$ & $\left(P_{1}, 0\right)$ & $\left(P_{1}, 0\right)$ & $\left(0, P_{2}\right)$ & $\left(0, P_{2}\right)$ \\
\hline
\end{tabular}
Table entries are (Profit to the Aggressor, Profit to the Defender)

By design, the weak-link structure of the contest described in Table 1 is such that the aggressor has a distinct advantage. While there are multiple mixed strategy Nash equilibria for this simultaneous move game (and no pure strategy equilibrium), each one is such that the aggressor should win with two-thirds probability and the defender should win with one-third probability. If however, the defender could observe the action of the aggressor, then the defender would always be able to win the game. Thus, this game provides a setting where a successful prediction market should have a dramatic effect. As a final point on the contest, the structure of the game is such that even in a repeated play setting there is no opportunity for cooperation and no higher expected payoff can be achieved beyond that of the repeated play of the stage game equilibrium.

\subsection{Prediction Market Setup}

A market consists of five traders, each endowed with 500 lab cents, the market's currency. Every trader observes a distinct token that the aggressor allocated in either A or B, thus collectively the five traders know the total number of $A$ tokens out of a possible five the aggressor invested in A. Traders can buy and sell shares whose value in lab cents is equal to the percentage of $A$ tokens that are observed (that is a share is worth the number of tokens invested in A by the aggressor $/ 5 \times 100$ ). Traders buy and sell shares via a double auction 
market for two minutes. A trader is not endowed with shares, but can hold a short position so long as his cash endowment is sufficiently large to cover the maximum possible value of the share. $^{2}$

\subsection{Treatments and Procedures}

To explore the impact of prediction markets on decisions of contestants, we conducted two main treatments of contests with and without prediction markets, referred to as "No Market" and "With Market". All sessions were completed at the Economic Science Institute at Chapman University. Subjects, none of whom had participated in any related studies, were drawn from a database of undergraduate volunteers.

In the "No Market" treatment, six fixed pairs of subjects completed the simultaneous version of the contest game described above. ${ }^{3}$ To maintain anonymity among subjects, several pairs participated the experiment at the same time. Each pair played the contest 23 times, including three practice rounds and 20 salient rounds with $P_{1}=P_{2}=\$ 2$. As demonstrated by Chowdhury et al. (2013), the fixed matching protocol leads to mixing behavior that is more consistent with theoretical prediction in Blotto style games. After each contest, both players were informed of the rival's action as well as the outcome. Subjects for this treatment were recruited for one hour. At the end of the experiment, contestant were privately paid their cumulative earnings in cash and dismissed from the experiment. A copy of the instructions for the contest game is included in the appendix.

The "With Market" also had six fixed aggressor - defender pairs playing the contest game. The first mover aggressor made her decision, then the traders in the prediction market each received a signal identifying a distinct token invested by the aggressor. Before making her own decision, the second mover defender could not observe aggressor's decision but could observe trading in the prediction market. ${ }^{4}$

Exogenous vs Endogenous Markets: Prior to the start of the contest, traders went through a sequence of ten trading markets where the number of A tokens was exogenously

\footnotetext{
${ }^{2}$ Deck, et al. (2013) demonstrate by comparison to Oprea, et al. (2007) that this procedure as opposed to providing an endowment of shares does not impact market performance in similar settings.

${ }^{3}$ Strictly speaking the actions were sequential, but the first mover aggressor's actions were kept hidden from the second mover defender so there was no information revelation. This was done because the other two treatments required contests decisions be made sequentially so that defenders could observe the market activity of the informed traders.

${ }^{4}$ In the with market treatment, each aggressor - defender pair experienced both private markets, observed only by the defender, and public markets, observed by both the defender and the attacker. The order of the public and private periods was blocked to control for order effects. Ultimately, the observability of the market did not impact behavior and in the results that are presented in the next section data from both types of markets are combined.
} 
determined. Thus, this portion of the experiment can be directly compared to other prediction market experiments, although it does mean that the results for markets predicting endogenous behavior are conditioned on having experienced traders in the markets something that is expected to facilitate information aggregation. Prior to the thirty planned markets (10 with exogenous token determination and 20 with endogenous determination) subjects were given instructions (a copy of which is included in the appendix), completed a comprehension quiz, and participated in an unpaid practice market. The subjects in a market interacted with each other every period, as is typical in market experiments. Further, each group of five traders was always connected to the same fixed aggressor - defender pair in the endogenous periods, but there were always multiple groups running concurrently to maintain anonymity. This type of familiarity between the traders and defender is reflective of naturally occurring internal prediction markets.

Contestants Experience Markets: The subjects who would serve as the contestants in these sessions also went through the market directions, practice period and the ten exogenously determined token allocation trading periods so that they would better understand the market feedback during the endogenous periods. In fact, the future contestants did not know that they would serve as contestants until after the ten initial markets were completed. ${ }^{5}$ After the last exogenous market all subjects in the session were informed of how the contest game worked and how the aggressor's actions would determine the information in the market. The experimental design is summarized in Table 2.

Table 2. Treatment Design

\begin{tabular}{lcc}
\hline \hline & No Market & With Market \\
\hline Number of Aggressor - Defender Pairs & 6 & 6 \\
Prediction Market & None & 5 Traders \\
Number of Subjects & 12 & 42 \\
Number of Periods & - & 10 \\
$\quad$ Exogenous Markets & 20 & 20 Planned* \\
\hline Contests & 20 & \\
\hline \hline
\end{tabular}

Notes: Due to time constraints, sessions with prediction markets lasted either 17 or 19 periods instead of the planned 20.

\footnotetext{
${ }^{5}$ Care was taken to ensure that an aggressor - defender pair did not participate in the same exogenous single prediction markets. Given the number of subjects needed for the endogenous prediction market portion of the session, the future contestants traded in markets with only 3 active traders during the exogenous markets phase of the session. These participants were informed that there were only three active traders in their market and that one of the inactive traders was given an A token and the other was given a B token so that the active traders as a whole still held complete information in a five token environment.
} 
Subjects in the prediction market sessions were recruited for two and half hours. All trader earnings were converted into $\$ U S$ at the rate of 500 lab cents = US\$1, a rate that was common knowledge throughout the experiment. At the end of the experiment, subjects were paid their earnings privately in cash and dismissed from the experiment. The average salient earnings were $\$ 11.63$ per hour, which was in addition to a fixed $\$ 7$ payment for participating.

\section{Results}

The data consist of choices in 228 contests and 168 prediction markets (see details in Table 2). Our results are organized around three main questions:

1. Do prediction markets perform differently when private information is exogenously determined versus when private information reflects strategic decisions?

2. Do prediction markets aid defenders in winning the contest?

3. Do aggressors in contests behave differently when they know there is a prediction market trading based on their decisions?

\subsection{Prediction Market Performance with Exogenous and Endogenous Information}

To examine whether prediction markets perform differently when the information is exogenous or endogenous, we investigate three key outcome variables: the closing price, the excess bids, and the number of contracts. ${ }^{6}$ Market closing prices are often used instead of average contract prices because the trading process gathers and refines information over the course of the trading period. In the last half of the exogenous token markets, the closing prices and the true values of the assets averaged 60.6 and 40 respectively, and the correlation between the average closing and the true asset value was 0.24 , consistent with the level of information aggregation in previous lab experiments (see e.g., Deck et al. 2013). ${ }^{7}$ Excess bids are defined as the number of unfulfilled standing bids minus the number of unfulfilled standing asks in a market period. Previous research has found that this measure contains useful information for making inference in asset markets (see Smith et al. 1988; Caginalp et al. 2000). In particular, excess bids indicate buying pressure and thus undervalued assets, while excess asks (i.e., excess bids being negative) suggest selling pressure and overvalued assets. The third measure is the number of contracts or trade volume, which is a standard measure of market activity.

\footnotetext{
${ }^{6}$ In some of the markets with endogenous information there were no trades. In these cases the closing price was taken to be the average of the lowest standing ask and highest standing bid when the market closed. In one instance there was no standing ask when the market closed and the closing price was calculated based upon an assumed ask of 100 .

${ }^{7}$ The substantive results do not change if we focus on average prices instead of closing prices. Across all 168 prediction markets, the correlation between average and closing prices was 0.78 . For the exogenous markets the average average price was 57.6 and the correlation with the true values was 0.36 .
} 
Table 3 reports regressions on each of the three market outcome variables described above. To control for correlations caused by repeated observations, we cluster at the level of aggressor-defender pairs. The first regressor "endogenous" is 1 if the signals received by traders are based on the actual decisions of the aggressor, and is 0 if signals are exogenously generated. The second regressor "value" is the true value of the asset.

Result 1. The pricing performance of prediction markets does not depend on whether the information is generated by strategic human decision makers or determined exogenously, but trade volume is affected.

Evidence. The first two columns of Table 3 indicate that neither closing prices nor excess bids are affected by the treatment variable; however the third column indicates that trade volume is lower when information is endogenous.

As one would expect, value has a positive and significant impact on the closing price the more the asset is worth, the greater the price. However, the effect is much smaller than it would be if closing prices equaled the true asset value (the point estimate would be 1 ). The positive slope on Value combined with the positive and significant constant term in the first regression indicates closing prices tend to be too high on average, particularly when the true value is low. This is consistent with previous prediction market experiments. The second regression reveals that the number of excess bids correlates with the true value. When the value is high, there are more people placing unfulfilled bids whereas when the price is low there are relatively more unfulfilled offers to sell. This too is consistent with previous prediction market experiments. The number of contracts, on the other hand, does not vary with the asset's value. This finding is important because it indicates that the traders were not liquidity constrained when the asset value was high. The third regression also reveals that the markets are fairly active although they are more active with exogenous information.

Table 3. Performance of Prediction Market

\begin{tabular}{|c|c|c|c|}
\hline & Closing Price & Excess Bids & Contracts \\
\hline \multirow[t]{2}{*}{ Endogenous } & -9.921 & -0.805 & $-3.032 * *$ \\
\hline & $(5.308)$ & $(0.933)$ & $(1.068)$ \\
\hline \multirow[t]{2}{*}{ Value } & $0.243^{* *}$ & $0.051 * * *$ & -0.009 \\
\hline & $(0.081)$ & $(0.013)$ & $(0.011)$ \\
\hline \multirow[t]{2}{*}{ Constant } & $51.587 * *$ & $-2.645^{*}$ & $12.345 * * *$ \\
\hline & (3.915) & $(1.274)$ & (2.259) \\
\hline $\mathrm{R}^{2}$ & 0.186 & 0.191 & 0.049 \\
\hline Observations & 168 & 168 & 168 \\
\hline $\begin{array}{l}\text { In parentheses a } \\
\text { denote significar }\end{array}$ & $\begin{array}{l}\text { obust standard e } \\
\text { at the } 10 \%, 5 \% \text { ar }\end{array}$ & $\begin{array}{l}\text { lustered at the } \\
\text { levels respectiv }\end{array}$ & vel. ${ }^{*}, * *$ and ${ }^{*}$ \\
\hline
\end{tabular}




\subsection{The Usefulness of Prediction Markets for Defenders}

If Defenders are using the prediction market successfully it should improve the win rate over the case in which there is no prediction market available to them. This does not occur.

Result 2. Having access to a prediction market does not improve defender's chance of winning.

Evidence. In the absence of a prediction market, the defenders won $39 \%$ of the contests $(n=120)$, similar to the predicted one third win rate ( $p$-value $=0.36$, two sided proportion test). In comparison, when defenders have access to a prediction market, their win rate did not improve: $38 \%$ ( $p$-value $=0.88$, two sided proportion test). Had the prediction markets provided perfect information and defenders fully taken advantage of this information, then defenders should be winning $100 \%$ of the time in the "with market" treatment.

The lack of change in defender win rates indicates they were not able to use the prediction markets to improve their chance of winning. This could be driven by two factors: 1 ) the markets may not have aggregated information and 2) the defenders may not have been able to decipher the information from the market and use it accordingly. Therefore, we next turn our attention to the analysis of prediction markets.

Figure 1 details each aggressor-defender pair in the prediction market treatments. This figure highlights the heterogeneity in aggressor play, which is captured by the asset value after the initial 10 exogenous value periods (shown as $x$ in the figure). In two of the sessions (sessions 4 and 5 ) the aggressor always invests all of his tokens in single target. In these cases the prediction markets appear to work well, as shown by the solid lines representing closing market prices. Of course, this performance could be facilitated by traders learning that the aggressors only take extreme actions. In the other cases where the aggressors occasionally split their tokens, interpreting what is happening in the prediction market is more difficult. Figure 1 also shows the actions of the defender. Given the structure of the game, the defender wins if he has the same number of A tokens as the aggressor or one more A token than the aggressor. Thus, there are two choices by the aggressor for which the defender could win given the defender's choice - essentially these are the defender's guesses about the aggressor's action. These choices are denoted by $\square$ in the figure with the top one being the number of $A$ tokens selected by the defender. If the defender won a particular contest the $\times$ will appear inside the $\square$. If the aggressor won then $\times$ will not appear inside the $\square$. As an example, consider the last period in session 4 (the top right of the Figure 1). In this period the aggressor selected $5 \mathrm{~A}$ tokens and thus the share value was 100 . The closing price was 90 and as a result the defender selected 5 A tokens. The defender won this contest. 
Figure 1. Prediction Markets: Asset Value, Aggressor's A Tokens, Closing Prices, and Defender's Guess of Aggressor Behavior

Exogenous

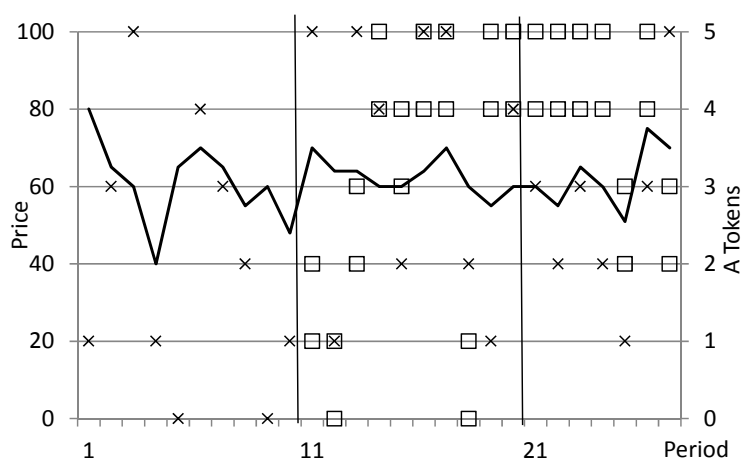

Session 1

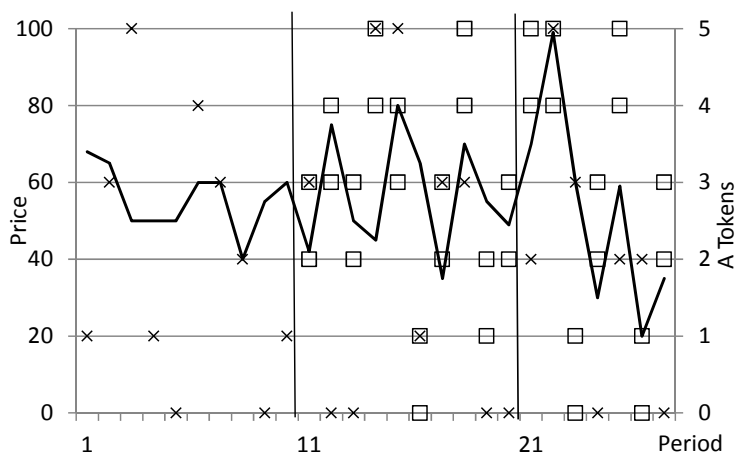

Session 2

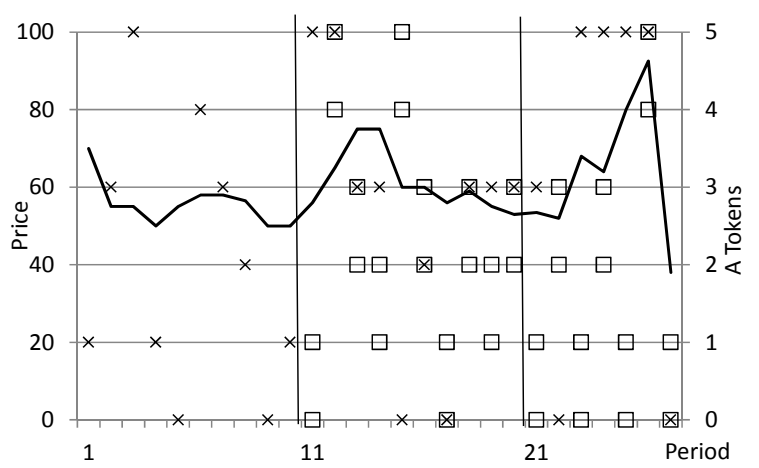

Session 3
Exogenous

Endogenous

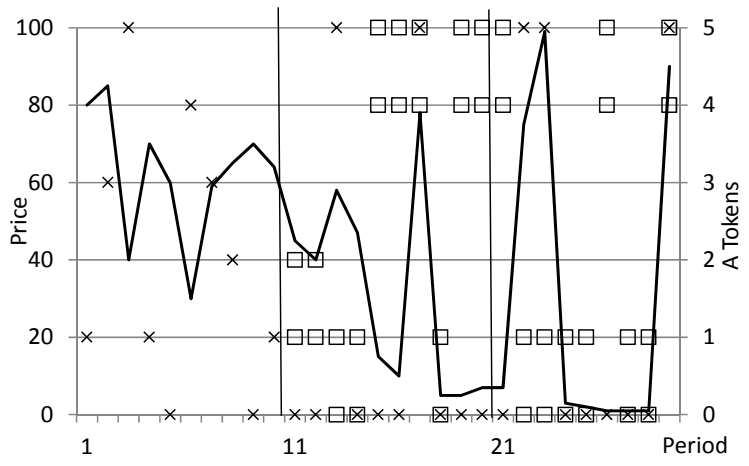

Session 4

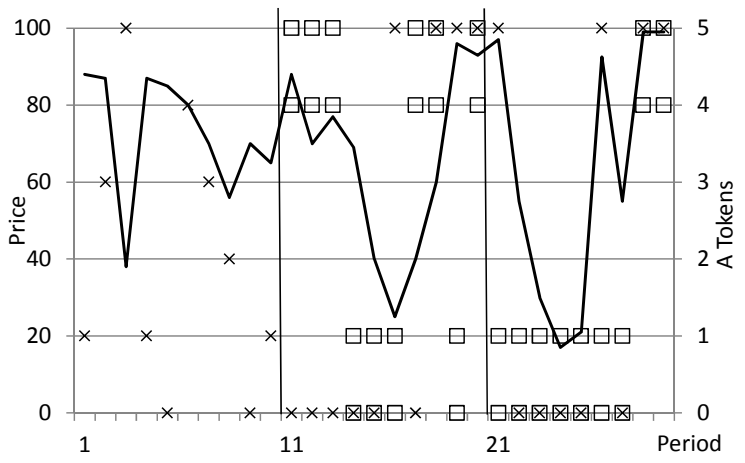

Session 5

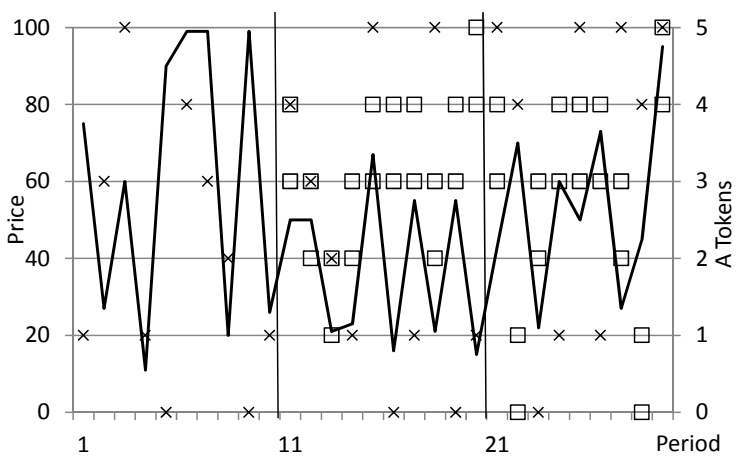

Session 6

- Closing Prices (left axis), $\times$ Aggressor's A Tokens (right axis) and Asset Value (left axis), $\square$ Aggressor Choices for which the Defender will win (i.e. the Defender's guess as to what the Aggressor did), the top one of which is the Defender's A Tokens. If the $\times$ appears inside the $\square$ then the defender won the contest. Otherwise the aggressor won the contest. 
Table 4 provides two sets of additional regression results designed to evaluate market and defender performance. The first looks at the degree to which the market provides useful information about the behavior of aggressors. That is, the estimation indicates what market information, if any, a defender should use to make inference about an aggressor's actions. The second regression in Table 4 reveals the market information that defenders actually use to make their decisions when a prediction market is in operation. Trade volume is omitted from these specifications because the results of Table 3 indicate there is no relationship between asset value and the number of contracts. The econometric results lead to the following.

Result 3. Prediction markets contain reliable information regarding Aggressor's decisions, but defenders fail to fully extract the information. Specifically, while Defenders correctly anticipate that closing prices are correlated with Aggressor behavior, Defenders fail to recognize that excess bids are as well.

Evidence. The estimation reported in Table 4 indicates that both closing price and excess bids provide information to the defender, consistent with previous prediction market experiments. However, it turns out that defenders are using closing price, but they are ignoring the information in excess bids at their own peril. Combined with the lack of an effect for the source of the information (see Table 3 ) and the similarity of our exogenous prediction markets and others in the literature, the regression results in Table 4 suggest that the failure of the prediction markets to help defenders lies at least partially with the ability of the defenders to interpret the prediction markets.

Table 4. Prediction Market Information that Defenders Should and Do Use

\begin{tabular}{ccc} 
& Should Use & Actually Use \\
\hline Dependent Variable & $\begin{array}{c}\text { Number of Tokens } \\
\text { Aggressor Invested in A }\end{array}$ & $\begin{array}{c}\text { Number of Tokens } \\
\text { Defender Invested in A }\end{array}$ \\
\hline Closing Price & $0.026^{* * *}$ & $0.018^{*}$ \\
& $(0.006)$ & $(0.008)$ \\
Excess Bids & $0.178^{* * *}$ & -0.061 \\
& $(0.033)$ & $(0.035)$ \\
Constant & $1.171^{* *}$ & $2.096^{* * *}$ \\
& $(0.351)$ & $(0.531)$ \\
\hline $\mathrm{R}^{2}$ & 0.438 & 0.051 \\
\hline Observations & 108 & 108 \\
\hline Standard errors, shown in parentheses are clustered at the session level. ${ }^{*}, * *$ and & \\
significance at the 10\%, $5 \%$ and $1 \%$ levels respectively. & \\
\hline
\end{tabular}

Result 3 reveals that, when used optimally, the prediction market would have increased defender win rates above the observed $38 \%$. Had the defenders used the estimation from the 
first column of Table 4 to forecast aggressor behavior and responded accordingly, their win rate would have reached $51 \%$. While this is still well below the $100 \%$ that would have been obtained from a perfectly functioning prediction market, this represents a marginally significant improvement (based on permutations test of difference between observed and potential win rates by individual defenders, $p$-value $=0.094)$.

\subsection{The Impact of Prediction Markets on Aggressor Strategy}

Another potential impact of the existence of prediction markets is on the behavior of aggressors. Knowing that their behavior will be revealed to traders and potentially relayed to defenders could lead aggressors to behave differently.

Result 4. The presence of a prediction market alters the behavior of the Aggressors.

Evidence. Figure 2 shows the behavior of aggressors by treatment taking into account the symmetry in the game. ${ }^{8}$ Because the defender has an extra token and wins ties, investing 0 or 6 tokens in $A$ is a dominated strategy for the defender. Figure 2 indicates that defenders understood this and almost always avoided placing all of their tokens in one place. The data indicate that markets actually lead aggressors to make significantly more extreme attacks, with increased weight on 0 or 5 tokens being invested in $A$ ( $p$-value $=0.01$, two-sided proportion test between treatments for frequency of investing 0 or 5 in A). The change in aggressor behavior is met with a change in defender behavior. Defenders in the treatment with prediction markets respond by investing 1 or 5 tokens in A to defend against these more extreme attacks ( $p$-value $=$ 0.01 , two-sided proportion test between treatments applied on frequency of investing 1 or 5 in A).

Figure 2. Contest Decisions by Treatment
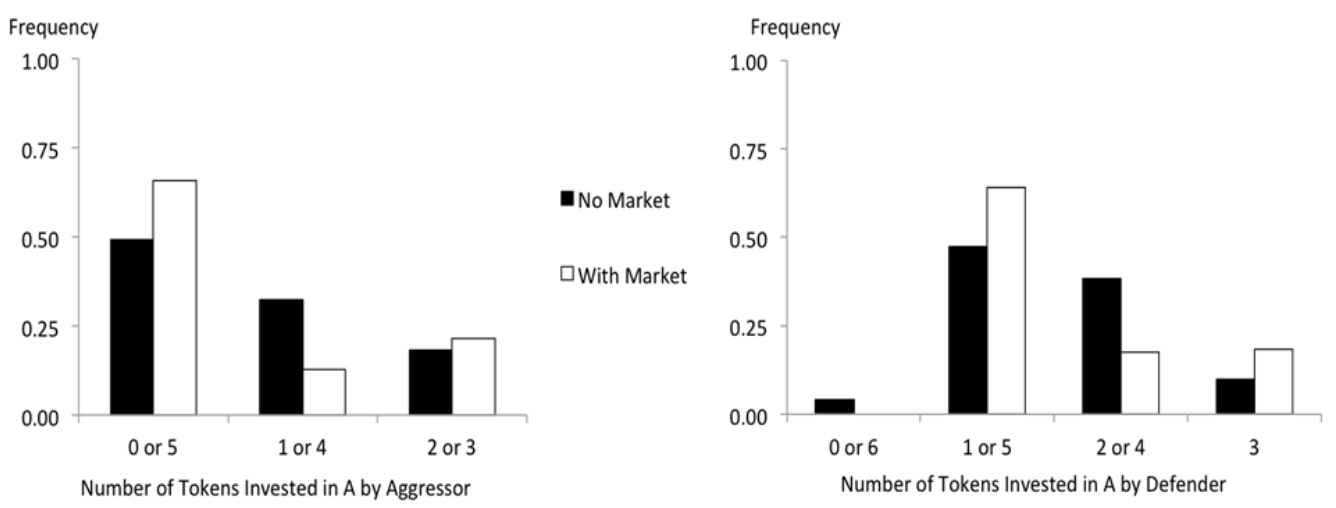

\footnotetext{
${ }^{8}$ Examining disaggregated data leads to the same general conclusions and supports that play is basically symmetric about the mean number of tokens although defenders without a prediction market are more likely to invest 4 tokens in A than 2 tokens in $\mathrm{A}$.
} 


\section{Discussion}

Prediction markets are becoming a broadly accepted tool for aggregating disparate pieces of information. Such markets have been used to predict a wide range of future outcomes, from the probability of extra-terrestrials making contact with earthlings (on Intrade.com) to the likelihood that a Hollywood movie set to be released years in the future will be a success (on HSX.com). These markets are also used by business for far more mundane forecasts of market conditions and rival behavior, which are then used to make strategic choices for the firm. However, much of the academic research investigating prediction markets has relied upon studies where the information being forecasted is exogenously determined.

In this paper we report the results of a series of controlled laboratory experiments in which players are competing in a strategic weak-link styled contest. Absent a prediction market, the contest is designed to heavily favor one of the players and this pattern is indeed what we observe behaviorally. However, a successful prediction market should turn the tide in favor of the other player. Ultimately, we do not find evidence that the disadvantaged player was able to use the prediction market to gain the upper hand. This failure appears to be at least partly due to the contestants not making full use of the information in the markets, specifically information contained in excess bids.

Our results demonstrate three important aspects of using prediction markets to forecast endogenously created strategically valuable information. The first is that the existence of a prediction market can alter the behavior being forecasted. Such a phenomenon could be particularly problematic if the traders are familiar with the strategic setting and overweight historical information that may no longer be relevant. The second insight of this paper is that market performance in terms of prices and excess bids is similar when the predicted information is exogenous versus when it is endogenous. This result is important because it suggests that the market incentives can be sufficient to help traders focus on their actual information rather than trading on their prior beliefs. The third highlight of our results is that while prices in prediction markets contain information, decision makers may ignore other information from the market at their own peril. Our study also adds to growing evidence that excess bids are an important source of information in prediction markets. Ceteris paribus, the more unfulfilled bids in the market the greater the forecast should be adjusted up from the price with the reverse holding for excess asks.

Our work demonstrates that the creation of a prediction market is not a panacea. Having a prediction market is not sufficient for decision makers to make good choices: what to take from a prediction market is not self-evident. Consumers of prediction market information need to be sufficiently sophisticated and trained to be able to fully exploit the advantages of having such markets. Of course, contestants who know they are facing more sophisticated rivals may 
further adjust their own behavior which could in turn influence market performance. We believe that this is an important avenue for future research as more and more organizations begin to implement prediction markets as inputs to important strategic decisions.

\section{References}

Anderson, Lisa R., and Charles A. Holt. 1997. "Information Cascades in the Laboratory." The American Economic Review 87(5): 847-862.

Arrow, Kenneth J., Robert Forsythe, Michael Gorham, Robert Hahn, Robin Hanson, John O. Ledyard, Saul Levmore, et al. 2008. "The Promise of Prediction Markets." Science 320 (5878): 877-878. doi:10.1126/science.1157679.

Arad, Ayala. 2012. "The Tennis Coach Problem: A Game-Theoretic and Experimental Study." The B.E. Journal of Theoretical Economics 12 (1) ISSN (Online) 1935-1704. doi: 10.1515/19351704.1738.

Arad, Ayala, and Ariel Rubinstein. 2012. "Multi-dimensional Iterative Reasoning in Action: The Case of the Colonel Blotto Game." Journal of Economic Behavior \& Organization 84 (2): 571585. doi:10.1016/j.jebo.2012.09.004.

Avrahami, Judith, and Yaakov Kareev. 2009. "Do the Weak Stand a Chance? Distribution of Resources in a Competitive Environment." Cognitive Science 33 (5): 940-950.

doi:10.1111/j.1551-6709.2009.01039.x.

Berg, Joyce E., and Thomas A. Rietz. 2003. "Prediction Markets as Decision Support Systems." Information Systems Frontiers 5 (1): 79-93.

Borel, Emile. 1953. "The Theory of Play and Integral Equations with Skew Symmetric Kernels." Econometrica 21 (1): 97-100. doi:10.2307/1906946.

Emile Borel, and J. Ville. 1938. Application de la theorie des probabilités aux jeux de hasard. Gauthier-Villars, Paris. In: Borel, E., Cheron, A. (Eds.), Theorie mathematique du bridge a la porteé de tous. Éditions Jacques Gabay, Paris, (1991)

Chen, Kay-Yut, and Charles R. Plott. 2002. "Information aggregation mechanisms: Concept, design and implementation for a sales forecasting problem." California Institute of Technology Social Science Working Paper 1131

Chowdhury, Subhasish M., Dan Kovenock, and Roman M. Sheremeta. 2009. "An Experimental Investigation of Colonel Blotto Games." Economic Theory, 52(3): 833-861.

Cinar, Yetkin, and Türkmen, Göksel. 2012. "An Experimental Analysis of Colonel Blotto Games Under Alternative Environments." Iktisat Isletme Ve Finans, 27 (312): 39-57. 
Derek J., and Kai A. Konrad. 2007. "Contests with Multi-tasking." The Scandinavian Journal of Economics 109 (2): 303-319.

Cowgill, Bo, Justin Wolfers, and Eric Zitzewitz. 2009. "Using Prediction Markets to Track Information Flows: Evidence from Google." In Auctions, Market Mechanisms and Their Applications: First International ICST Conference, AMMA 2009, Boston, MA, USA, May 8-9, 2009, Revised Selected Papers. Edited by Sanmay Das, Michael Ostrovsky, David Pennock, and Boleslaw Szymanksi. Berlin.: Springer

Caginalp, Gunduz, David Porter, and Vernon Smith. 2000. "Momentum and Overreaction in Experimental Asset Markets." International Journal of Industrial Organization 18 (1): 187-204.

Dechenaux, Emmanuel, Dan Kovenock, and Roman Sheremeta. 2012. "A Survey of Experimental Research on Contests, All-pay Auctions and Tournaments." All-Pay Auctions and Tournaments (September 28, 2012).

Deck, Cary, Shengle Lin, and David Porter. 2013. "Affecting Policy by Manipulating Prediction Markets: Experimental Evidence." Journal of Economic Behavior \& Organization, 85: 48-62

Deck, Cary, and David Porter. 2013. "Prediction Markets in the Laboratory." Journal of Economic Surveys 27 (3): 589-603

Friedman, Lawrence. 1958. "Game-theory Models in the Allocation of Advertising Expenditures." Operations Research 6 (5): 699-709.

Fudenberg, Drew, Richard Gilbert, Joseph Stiglitz, and Jean Tirole. 1983. "Preemption, Leapfrogging and Competition in Patent Races." European Economic Review 22 (1): 3-31.

Gallardo, Paola, and Alexandra Heath. 2009. "Execution Methods in Foreign Exchange Markets." BIS Quarterly Review, March.

Gjerstad, Steven, and McClelland Hall. 2005. "Risk Aversion, Beliefs, and Prediction Market Equilibrium." Economic Science Laboratory, University of Arizona.

Golman, Russell, and Scott E. Page. 2009. "General Blotto: Games of Allocative Strategic Mismatch." Public Choice 138 (3-4): 279-299.

Gross, Oliver Alfred. 1950. "The symmetric Blotto game." Rand Corporation Memorandum, RM424

Gross, Oliver Alfred and R.A. Wagner. 1950. "A continuous Colonel Blotto game." Rand Corporation Memorandum, RM-408 
Hahn, Robert, and Paul Tetlock. 2005. "Using Information Markets to Improve Public Decision Making."

Harris, Christopher, and John Vickers. 1985. "Patent Races and the Persistence of Monopoly." The Journal of Industrial Economics 33 (4): 461-481.

Harris, Christopher, and John Vickers. 1987. "Racing with Uncertainty." The Review of Economic Studies 54 (1): 1-21.

Hart, Sergiu. 2008. "Discrete Colonel Blotto and General Lotto Games." International Journal of Game Theory 36 (3-4): 441-460.

1520. Hung, Angela A., and Charles R. Plott. 2001. "Information Cascades: Replication and an Extension to Majority Rule and Conformity-rewarding Institutions." The American Economic Review 91 (5): 1508-1520.

Kovenock, Dan, and Brian Roberson. 2010. "Conflicts with Multiple Battlefields". CESifo working paper: Empirical and Theoretical Methods.

Krueger, Anne O. 1974. "The Political Economy of the Rent-seeking Society." The American Economic Review 64 (3): 291-303.

Kvasov, Dmitriy. 2007. "Contests with Limited Resources." Journal of Economic Theory 136 (1): 738-748.

Laslier, Jean-François. 2002. "How Two-party Competition Treats Minorities." Review of Economic Design 7 (3): 297-307.

Laslier, Jean-Francois, and Nathalie Picard. 2002. "Distributive Politics and Electoral Competition." Journal of Economic Theory 103 (1): 106-130.

Manski, Charles. 2006. "Interpreting the Predictions of Prediction Markets." Economics Letters 91 (3): 425-429

Oprea, Ryan, David Porter, Chris Hibbert, Robin Hanson, and Dorina Tila. 2007. "Can Manipulators Mislead Market Observers." Manuscript, University of California Santa Cruz. Available at: http://hanson.gmu.edu/judges.pdf

Pearlstein, Steven. 2003. "Misplacing trust in the markets." Washington Post. 30 July Pennock, David M., Steve Lawrence, C. Lee Giles, and Finn Arup Nielsen. 2001. "The Real Power of Artificial Markets." Science, 291 (5506): 987-988.

Plott, Charles R., and Shyam Sunder. 1988. "Rational Expectations and the Aggregation of Diverse Information in Laboratory Security Markets." Econometrica 56 (5): 1085-1118. 
Polgreen, Philip M., Forrest D. Nelson, George R. Neumann, and Robert A. Weinstein. 2007. "Use of Prediction Markets to Forecast Infectious Disease Activity." Clinical Infectious Diseases 44 (2): 272-279.

Roberson, Brian. 2006. “The Colonel Blotto Game.” Economic Theory, 29 (1): 1-24.

Smith, Vernon L., Gerry L. Suchanek, and Arlington W. Williams. 1988. "Bubbles, Crashes, and Endogenous Expectations in Experimental Spot Asset Markets." Econometrica 56(5): 11191151.

Snyder, James M. 1989. "Election Goals and the Allocation of Campaign Resources." Econometrica 57 (3): 637-660.

Szentes, Balázs, and Robert W. Rosenthal. 2003. "Three-object Two-bidder Simultaneous Auctions: Chopsticks and Tetrahedra." Games and Economic Behavior 44 (1): 114-133.

Szentes, Balazs, and Robert W. Rosenthal. 2003. "Beyond Chopsticks: Symmetric Equilibria in Majority Auction Games." Games and Economic Behavior 45 (2): 278-295.

Tullock, Gordon. 1980. "Efficient rent seeking." in Toward a Theory of the Rent-seeking Society. Edited by James Buchanan, Robert D. Tollison, and Gordon Tullock. Texas A \& M University Press.

Wolfers, Justin, and Eric Zitzewitz. 2004. "Prediction Markets". National Bureau of Economic Research.

Wyden, R.and B. Dorgan 2003.Wyden, Dorgan call for immediate halt to tax-funded "Terror Market" scheme, Press Release, July 28. 


\section{Appendix: Subject Instructions}

\section{Text of Directions for Contest with No Prediction Market}

\section{Page 1.}

This is an experiment in the economics of decision making. You will be paid in cash at the end of the experiment based upon your decisions, so it is important that you understand the directions completely. Therefore, if you have a question at any point, please raise your hand and someone will assist you. Otherwise we ask that you do not talk or communicate in any other way with anyone else. If you do, you may be asked to leave the experiment and will forfeit any payment.

Page 2.

The experiment is broken into a series of rounds. Each round you can earn $\$ 2$ dollars. At the end of the experiment you will be paid your cumulative earnings.

You will be randomly and anonymously matched with someone else in the experiment and will interact with that person every round. Each round, one of you will earn $\$ 2$ and the other will earn $\$ 0$. The process used to determine who earns the money in a round is described on the following pages.

\section{Page 3.}

There are two items available each round: item A and item B.

There are also two types of people in this activity: First Movers and Second Movers. You will be a First (Second) Mover, but it is important that you understand both roles.

First Movers earn $\$ 2$ if they claim either item A or item B. Second Movers have to claim both item A and item $B$ to earn \$2.

To claim an item each person places a bid on the item using their tokens for that round. Whoever bids more tokens for an item claims it. There is no cost for the tokens and both people must use all of their tokens each round.

First Movers have 5 tokens and Second Movers have 6 tokens. Bids must be in integer amounts, but the Second Mover has an additional 0.5 tokens automatically bid on each item so a tie can never occur.

Your role, the number of tokens and the amount of money available is the same every round. No participant knows how many rounds there will be nor will anyone ever know with whom they were interacting. 
Page 4.

Here is an example of how bidding in a round might look.

Suppose the First Mover places a bid of 4 for item A and 1 for item B.

If the Second Mover places a bid of 5 for item A and 1 for item B, then the Second Mover's total bid for item A is 5.5 and 1.5 for item B. In this case, the Second Mover claims both items and thus the Second Mover earns $\$ 2$ while the First Mover earns $\$ 0$.

If instead the Second Mover places a bid of 6 for item A and 0 for item B, then the Second Mover's total bid for item A is 6.5 and 0.5 for item B. In this case, the Second Mover claims item A, but the First Mover claims item B and thus the First Mover earns $\$ 2$ while the Second Mover earns $\$ 0$.

Alternatively, if instead the Second Mover places a bid of 3 for item A and 3 for item B, then the Second Mover's total bid for item A is 3.5 and 3.5 for item B. In this case, the Second Mover claims item B, but the First Mover claims item A and thus the First Mover earns \$2 while the Second Mover earns \$0.

Page 5.

First Movers make their decisions before Second Movers do, but Second Movers do not observe the choices of the First Mover prior to making their own decisions. After each round, you will observe the amount each person bid for each item and your earnings for the round.

Page 6

To summarize

You have been assigned the role of First (Second) Mover and will retain that role throughout the experiment.

Each round you or the person you are matched with will earn $\$ 2$.

First Movers must claim either item A or item B to earn the money

Second Movers must claim both item A and item B to earn the money

Items are claimed by bidding tokens and whoever bids the most tokens for an item claims it.

First Movers have 5 tokens and Second Movers have 6 tokens plus an extra 0.5 tokens for each item. 


\section{Directions for Trading Markets}

\section{Instructions}

This is an experiment in market decision making. You will be paid in cash for your participation at the end of the experiment. Different participants may earn different amounts. What you earn depends on your decisions and the decisions of others. All money amounts are denoted in lab cents, which will be converted into \$US at the rate of 500 lab cents $=\$ 1$ US.

The experiment will take place through the computer terminals at which you are seated. If you have any questions during the instructions, raise your hand and a monitor will come by to answer your question. If any difficulties arise after the experiment has begun, raise your hand, and someone will assist you.

There will be several market rounds in this experiment. Each market round is separate, although your payoff will be the cumulative sum of your earnings in each market round.

You will be a Trader interacting with the same 4 other Traders every round.

There are 5 "tokens" each round that can be either A tokens or B tokens. Before a market round, each Trader will observe a different token, so each token is observed by exactly one Trader.

Traders can trade "Shares" that are worth either $0,20,40,60,80$, or 100 cents. The actual value of a share in a market round is determined by the percentage of $A$ tokens in a given round. If there are $3 \mathrm{~A}$ tokens, and thus 2 B tokens, then the value of a share is 60 cents as $3 / 5=60 \%$ of the tokens are A tokens. 
Notice that a share has the same value to every Trader. However, this value will only be revealed at the end of the round.

For the first several rounds, the number of $A$ tokens will be determined randomly. The number of $B$ tokens is always 5 minus the number of $A$ tokens. Once the number of $A$ and $B$ tokens is determined, each trader will be randomly assigned one of the five tokens to observe.

Later in the experiment, some of you will participate in a different activity and for the rest of you the way the number of $A$ and $B$ tokens is determined will change, but you will receive additional directions when that change occurs. Nothing you do in this part of the experiment will impact the number of $A$ and $B$ tokens in the second part of the experiment or who is selected to do the other activity.

Each round, Traders will start with 500 in "Cash" and can buy or sell shares if they wish. If a Trader buys a share, she pays the buying price of the share. If she holds the share until the end of the round then she earns the value of the share. If she sells a share that she bought previously during the round, she will receive the selling price but will not receive the value of the share at the end of the round.

If a Trader does not have a share, but still wishes to sell, she can create a share. Creating a share is identical to selling an existing share except that the seller will have to pay the buyer the value of the share. In order to make sure the seller creating a share can cover the value at the end of the round, the computer automatically takes 100 cents from the Trader and puts it into a reserve account to cover payment. So to create a share a Trader must have 100 in cash after adding the selling price, which the seller receives. Any money held in the reserve account that is not paid to the owner of the share is given back to the trader who sold the share after the round ends. 
Now we will describe a Trader's screen
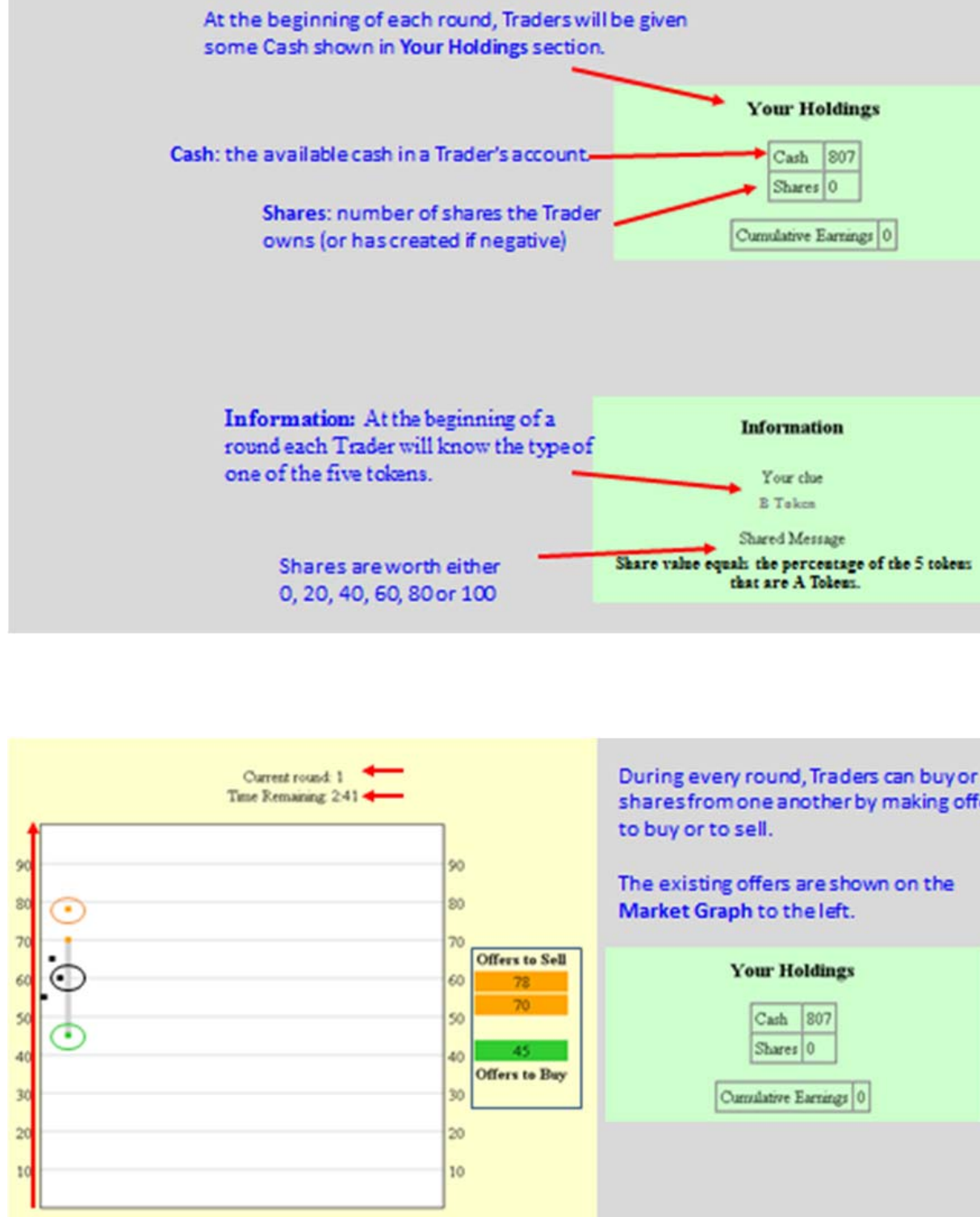

During every round, Traders can buyor sell shares from one another by making offers to buy or to sell.

The existing offers are shown on the Market Graph to the left.

On top of the graph, the Current round is shown.

Below that, the Time Remaining for the trading round is shown. Each round lasts two minutes. The vertical axis lists the Price for the offers.

Every time someone makes an offer to buy a share, a GREEN dot will appear on the graph to the left. Every time someone makes an offer to sell, an ORANGE dot will appear on the graph to the left. Once a trade is actually made, the trade will be shown as a BLACK dot in the graph.

Offers are alsolisted on the Market Book to the right of the graph. 

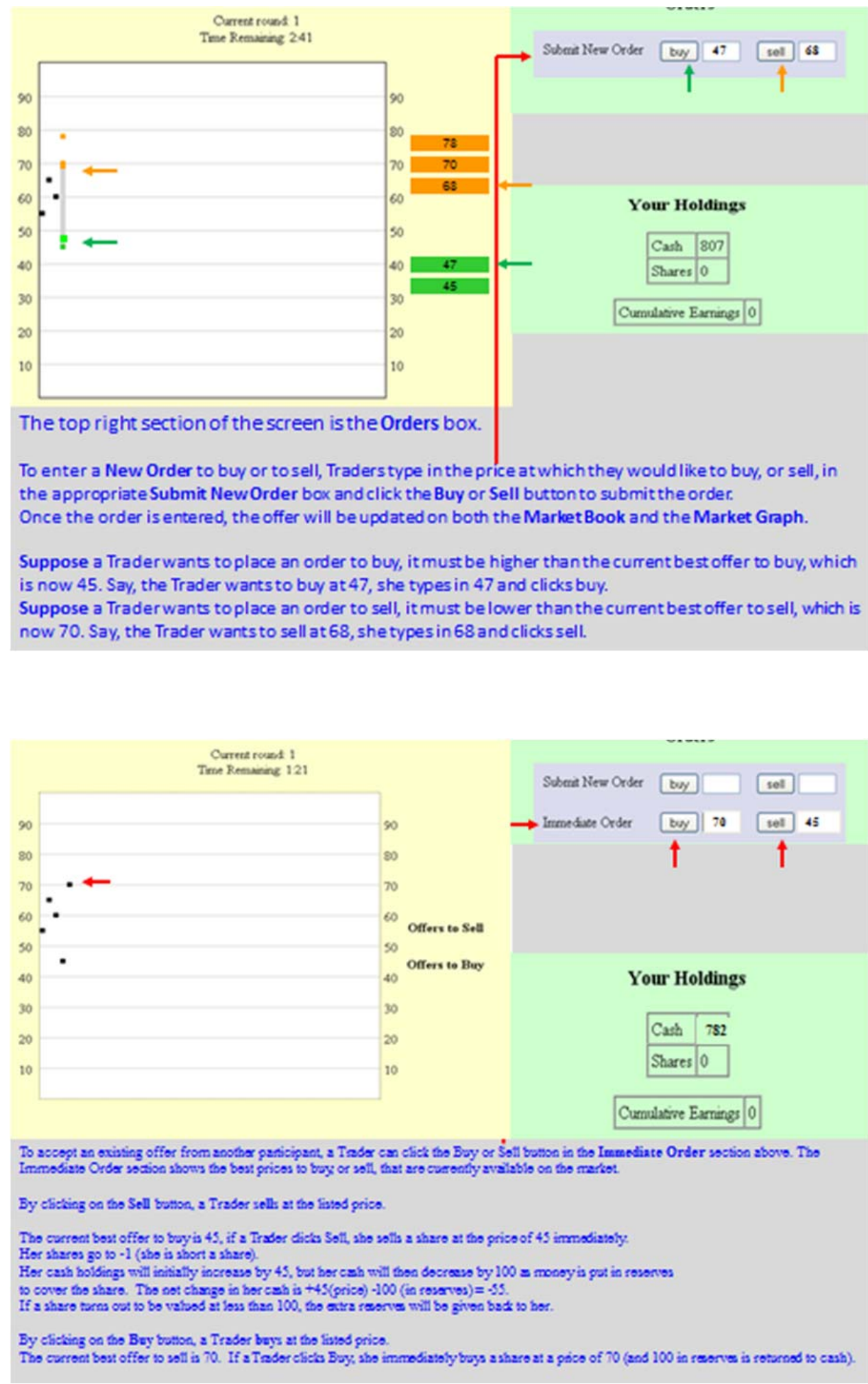

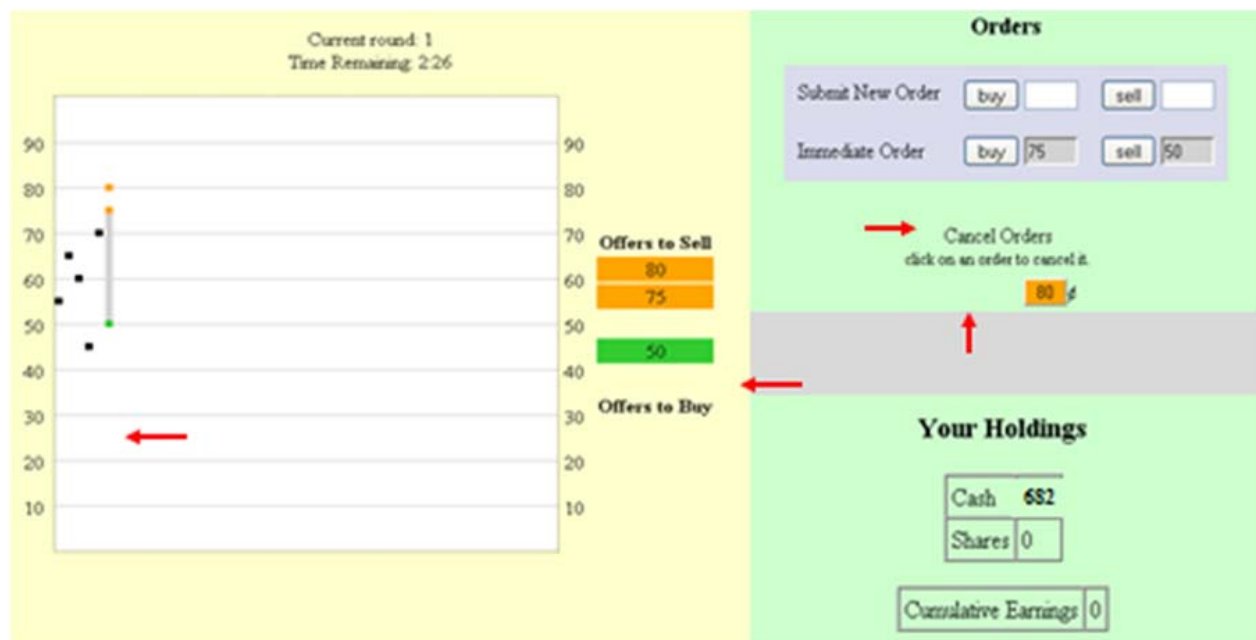

Whenever a Trader enters new offers to buy, or sell, she will have those offers appear as Buttons belowthe order box.

A Trader's outstanding offers to buy cannot exceed her cash hold ing; her outstanding offers to sell cannot exceed her ability to meet the reserves holdings.

Therefore, a Trader may have to delete offers under "Cancel Orders".

By clicking on these buttons, a Trader can take them off of the market.

Suppose a Trader clicks on the bid button 25 , she will remove it from the market:
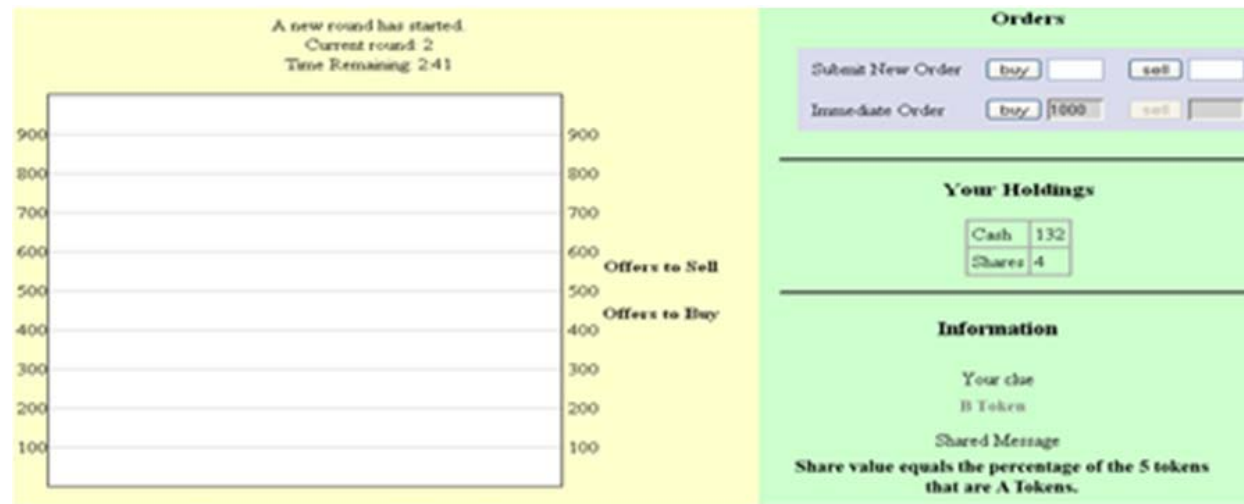

The share earnings each round will be added to the cash account of the holder. This amount is how much a Trader earns in a given round.

A Trader's earnings will accumulate eachround.

Her cash and shares do not carry over to the next round. 
Summary of Experiment for Traders

1. Traders will be given an initial amount of Cash and cancreate shares. The value of a share in lab cents is equalto the percentage of tokens that are A tokens (out of a totalof 5 tokens).

2. Each period, Traders will observe one of the 5 tokens and each trader will observea different token.

3. Traders can submit offers to BUY sharesand offers to SELL shares. If a Trader createsa share by selling a share when she does not have one, she will have to set 100 in a reserve account to make sure she can cover the payment to the share's owner.

4. Trades can make trades by buying at the current lowest offer to sell or selling at the current highest offer to buy.

A short quiz will appear on your screen in a moment. The purpose of th is is to make sure everyone understand how the experiment works and how payoff are determined.

After everyone completes the quiz, there will be an unpaid practice round to familiarize everyonewith the program. 